\title{
FACTORS AFFECTING ON RICE BRAN OIL EXTRACTION USING HYDRULIC PRESS UNIT
}

\author{
M. M. El-Kholy ${ }^{(1)}$ Matouk A.M. ${ }^{(2)}$ M.El-Sadany ${ }^{(3)}$ \\ and Y. T. Hendawy ${ }^{(4)}$
}

\section{ABSTRACT}

A study was carried out to test and evaluate the effect of bran heat stabilization, steaming process, applied pressure, and pressing time on the extraction efficiency of rice bran oil using a 32 ton hydraulic press unit. Four steaming periods (20, 25, 30, and $35 \mathrm{~min})$, six applied pressures (150,175, 200, 225, 250 and 275 bar), and four holding times (10, 15, 20 and $25 \mathrm{~min})$ were tested and evaluated. The bran samples were divided into two groups, the first group was left without stabilization (raw bran) while the second group was stabilized by heat treatment at heating surface temperature of $95^{\circ} \mathrm{C}$ and exposure time of 10 minutes (stabilized bran) as recommended by (Hendawy 2003). The results showed that, at all levels of applied pressure the moisture content of bran samples (raw and stabilized) increased with the increase of steaming time and it was also gradually increased with the increase of holding time up to 20 minutes and starts to decrease again at the holding time of $25 \mathrm{~min}$. Meanwhile, the percentage of extracted oil increased with the increase of steaming period, the applied pressure and the holding time. The extracted oil percentage of the steamed raw bran ranged from 31.1 to $46.98 \%$ in comparison with 11.87 to $26.94 \%$ for the un-steamed samples. While, it ranged from 23.94 to $38.19 \%$ for the stabilized steamed bran in comparison with 7.63 to $24.03 \%$ for the stabilized un-steamed samples. On the other hand, heat stabilization of the bran samples prior to steaming process causes a slight reduction in percentage of the extracted oil in comparison with the raw bran. On the same time, it has showed a reduction in the percentage of free fatty acids which in turn keep the extracted oil more stable during the storage process.

(1) Senior Researcher, Agric. Eng., Res. Inst. A.R.C. Dokki. Giza.

(2) Prof. of Agric. Eng., Agric. Eng. Dept. Fac. of Agric. Mansoura Univ.

(3)Assoc., Prof. Agric. Eng. Dept. Fac. of Agric. Mansoura Univ. 
(4) Assis., Researcher, Agric. Eng., Res. Inst. A.R.C. Dokki. Giza

\section{INTRODUCTION}

Tn Egypt, the cultivated area of rice is 1.534 million feddan which annually produces 6.38 million tons (RRTC, 2006). The bran, being an important by- product, is mainly produced during rice milling operation amounts to $10 \%$ of the weight of rice grain. It is rich in protein 13-16\%, oil 15-22 \%, fiber 6.2-14.4\%, ash 8-17.75\%, vitamins, and trace minerals (Daniel et al.,(1993). Rice bran oil is called the "heart oil", because used for cooking food, is found to be very delicious and has a high hypo cholesterolemic effect (Gupta, 1989). In Japan about 100,000 metric tons of high quality rice bran oil are annually produced, and commonly used in salad and cooking. Because of its better keeping qualities, defatted bran usually commands a higher price than untreated bran (Koga (1980). Yoon et al. (1994) reported that rice bran oil can be used for edible or industrial purpose. Only high quality rice bran oil (RBO) is used for edible purpose. Rice bran oil has better oxidative stability than its competitive products such as soybean oil or cotton seed oil because of its high tocopherol and low-linolenic- acid content. The removal of oil from oilseeds can be achieved by extraction, expression or a combination of them. Extraction is the process of separating a liquid from a liquid solid system with the use of solvents. Expression is the process of mechanically removing liquid contained in solids by the use of equipment such as screw presses, hydraulic presses, roll presses and mills (khan and Hannan 1983). In oil production expression and solvent extraction are competitive, expression is less thorough but may yield both oil and meal products of high quality. Contrary to oil extraction system using chemical solvent the residue after pressing can be used directly for human /animal foodstuffs because there is no chemical contamination. It is also unnecessary to refine the oil, since expression process has no negative influence on the oil quality. Although the solvent extraction process is more efficient than pressure extraction, solvent extraction equipment is expensive, there are fire and explosion hazards, and the technology is too complicated to be used on village level (Singh, et al., 1984). So, the solvent extraction is not suitable for small and medium-size oil mills. The mechanical expression of oil from oilseeds is the most 
widely used method for oil extraction. Koga (1980) reported that other than solvent extraction system there is a method of oil extraction by pressing. This is widely used for oil extraction from rape seed, cotton seed, peanut, coconut and for bran oil extraction also. In the case of rice bran only about half of the contained oil, i.e. 9 to $10 \%$ of bran weight is extracted by pressing. However, the pressing method has advantages over solvent method such as the cost of equipment can be much less as the system is simpler and the minimum economic scale is smaller, the operation is easier and dose not require skilled labor, the operation dose not use volatile solvent, no danger of fire hazard nor explosion, small capacity equipment can be designed so as to be coupled directly with the existing small or medium scale rice mills, i.e. 2 to 4 ton of baddy per hour and the remaining oil in bran cake not only improves the calorific value of the feed but also gives the effect of accelerating animal growth. Bor (1991) reported that wet heat treatment is used to free the lipids from other components in oil seeds to facilitate oil extraction. The major function of heat treatment of rice bran, however, is to inactivate the lipolytic enzymes (lipases) present in native bran. Lipases catalyze the hydrolysis of glyceried into free fatty acids and glycerol and increase the percentage of free fatty acids. Sivala et al. (1991) studied the effect of moisture content on oil expression from rice bran. They indicated that oil yield depend on processing parameters such as pressure and moisture content. They also found that as compression and oil drains from the system the applied load is slowly transferred to the rigid structure of the solid cake, and that even if some oil is trapped in the cake matrix, it cannot be expelled because the particles from a solid skeleton and prevent the load from being transferred to the oil. They also mentioned that in the processing of oilseeds for oil expression, water is sprinkled as a pretreatment to increase the moisture content for better extractability. The experiments were designed based on response surface methodology to determine the best method to apply pressure, pressing time and moisture content for maximum oil recovery. Prediction equations were also generated by Sivala et al., (1991) for oil recovery and found to be nonlinear within the range of factors studied, namely 7 to $30 \mathrm{MPa}$ applied 
pressure, 8 to 42 min pressing time and 8.3 to $11.7 \%$ moisture content (w.b.).

The present experimental work aims to study and evaluate the effect of bran stabilization, steaming process, applied pressure, and pressing time on the extraction efficiency of rice bran oil using a hydraulic press unit.

\section{MATERIAL AND METHODS}

\section{Material:}

Fresh rice bran used for the experiments was taken from a rice variety (Sakha101) which was harvested from the farm of Rice Mechanization Center and milled immediately after natural drying to a moisture level of about $14 \% \pm 1$ w. b. using Satake rice mill model (SB10-D). The produced rice bran was filled in plastic bags and stored temporarily in a freezer adjusted at a temperature of $\left(-5^{\circ} \mathrm{C}\right)$ in order to suppress fungal growth and minimize quality changes.

\section{Equipment:}

\section{The conduction heating unit:}

An experimental scale rotary conduction heating unit was used for the bran stabilization. The unit consists of a rotary cylinder $(0.6 \mathrm{~m}$ diameter and $0.2 \mathrm{~m}$ long $)$ inclosed by a fixed insulated cylinder $(0.8 \mathrm{~m}$ diameter and $0.3 \mathrm{~m}$ long). The rotary cylinder connected to a driving mechanism and a $0.5 \mathrm{~kW}$ low speed motor with different sizes of pullies for power supply. Detailed descriptions of the heat stabilization unit are presented in figure (1).

\section{Steaming unit:}

A small-scale steaming unit was designed and fabricated at the workshop of Rice Mechanization Center (R.M.C.). The unit consists of $2 \mathrm{~mm}$ thick stainless steel water tank of dimensions of $65 \mathrm{~cm}$ long, $55 \mathrm{~cm}$ wide and 45 $\mathrm{cm}$ high. The tank was covered by a heavy steel cover and a rubber gasket to prevent steam leakage. A stainless steel screen sheet was rested inside the water tank at $25 \mathrm{~cm}$ distance from the bottom to accommodate the bran mats during the steaming process. The water tank and other parts were carried out over an iron frame with dimensions of $(67 \times 57$ x 100 $\mathrm{cm})$ built up from steel angles $(25 \times 25 \mathrm{~mm})$. The heating process of the water tank was conducted through a butane gas heating source. Fig.(2) shows the schematic diagram of the steaming unit. 


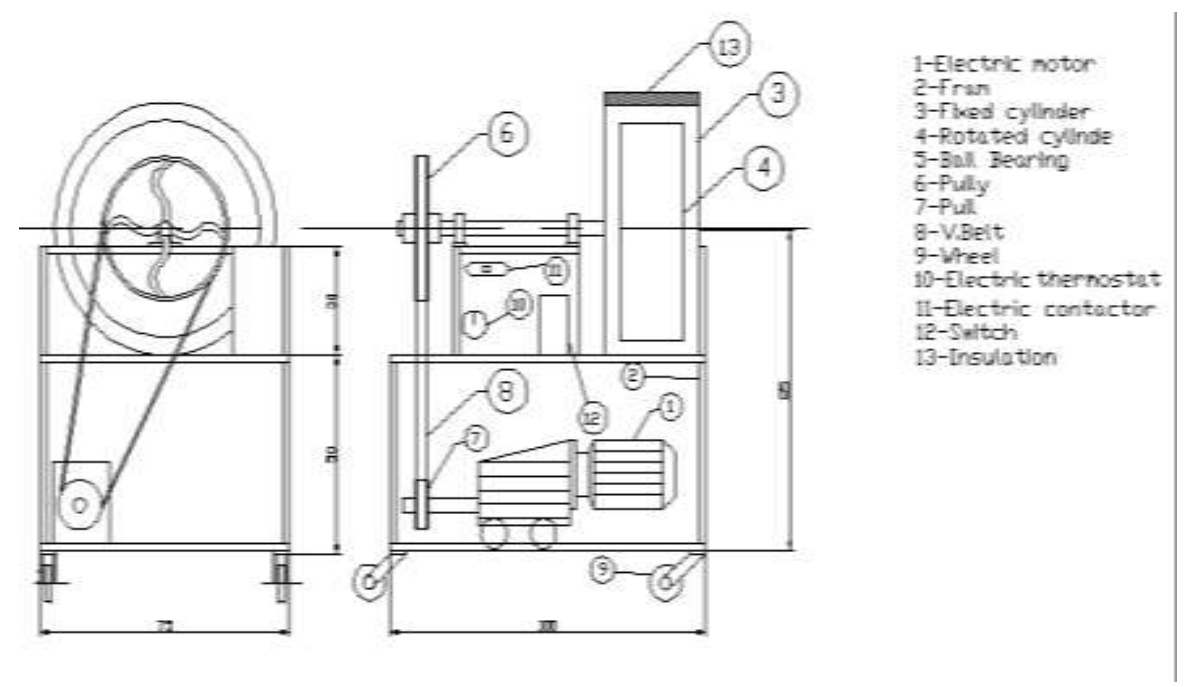

Fig.(1) Schematic diagram for the conduction heating unit

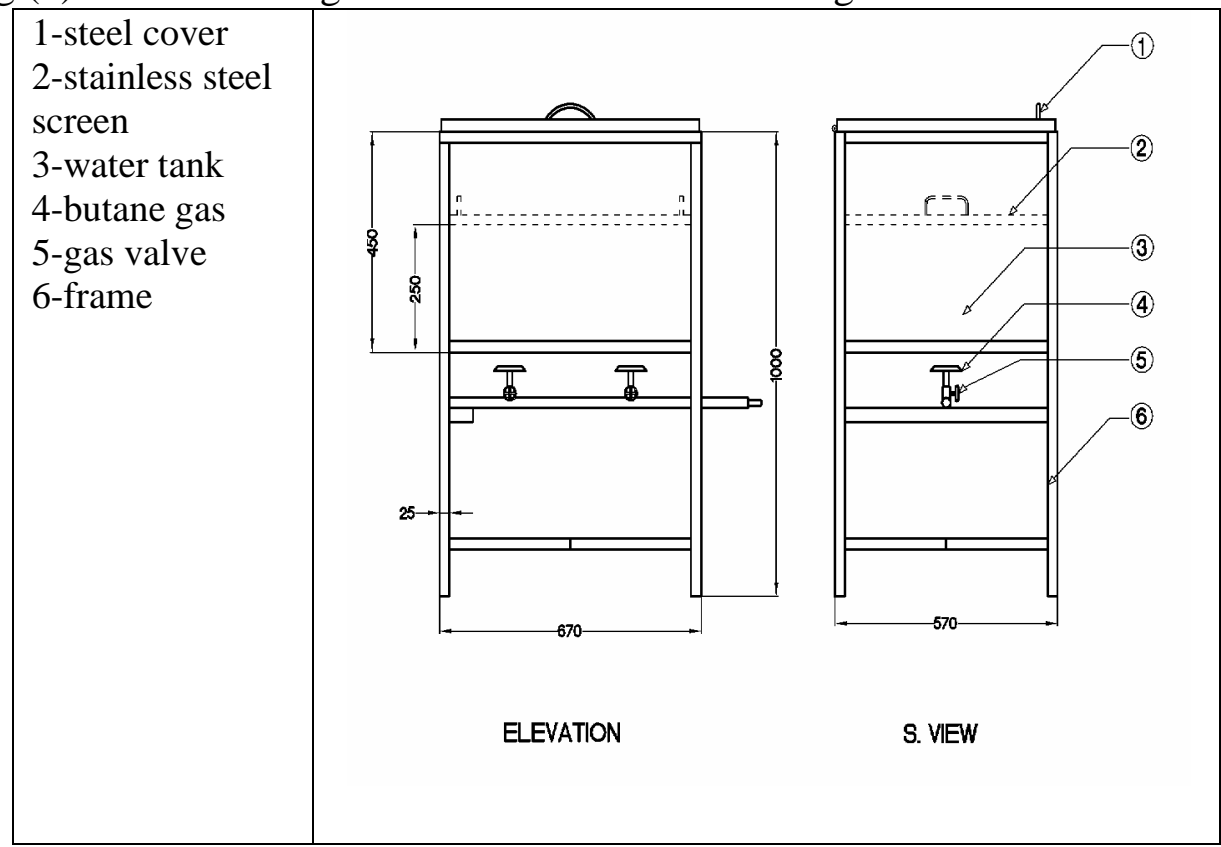

Fig. (2) Schematic diagram of the steaming unit

\section{The hydraulic press unit:}

A 32 tons manual hydraulic piston with pressure gauge and stainless steel perforated cylinder rested over a stainless steel oil receiving tray were used for bran oil extraction. Detail descriptions of the hydraulic press unit are presented by (Matouk et al., 2008). Schematic diagram for the hydraulic press unit is shown in fig. (3).

Misr J. Ag. Eng., January 2009 


\section{Experimental treatments}

Four steaming periods $(20,25,30$, and $35 \mathrm{~min})$, six applied pressures $(150,175,200,225,250$, and 275 bar), four holding times (10, 15, 20 and $25 \mathrm{~min}$ ) and two types of bran (raw and stabilized) were used for the experimental work.

\section{Test procedure and measurements:}

Before each experimental run, rice bran samples were taken out from the freezer and left at the ambient temperature until the initial temperature of the bran approached a level at or around that of the ambient temperature. The bran samples were divided into two groups, the first group left without any treatments (raw bran) while the second group was heat treated using the rotary heat stabilizer at heating surface temperature of 95 ${ }^{\circ} \mathrm{C}$ and exposure time of 10 minutes as recommended by (Hendawy, 2003).

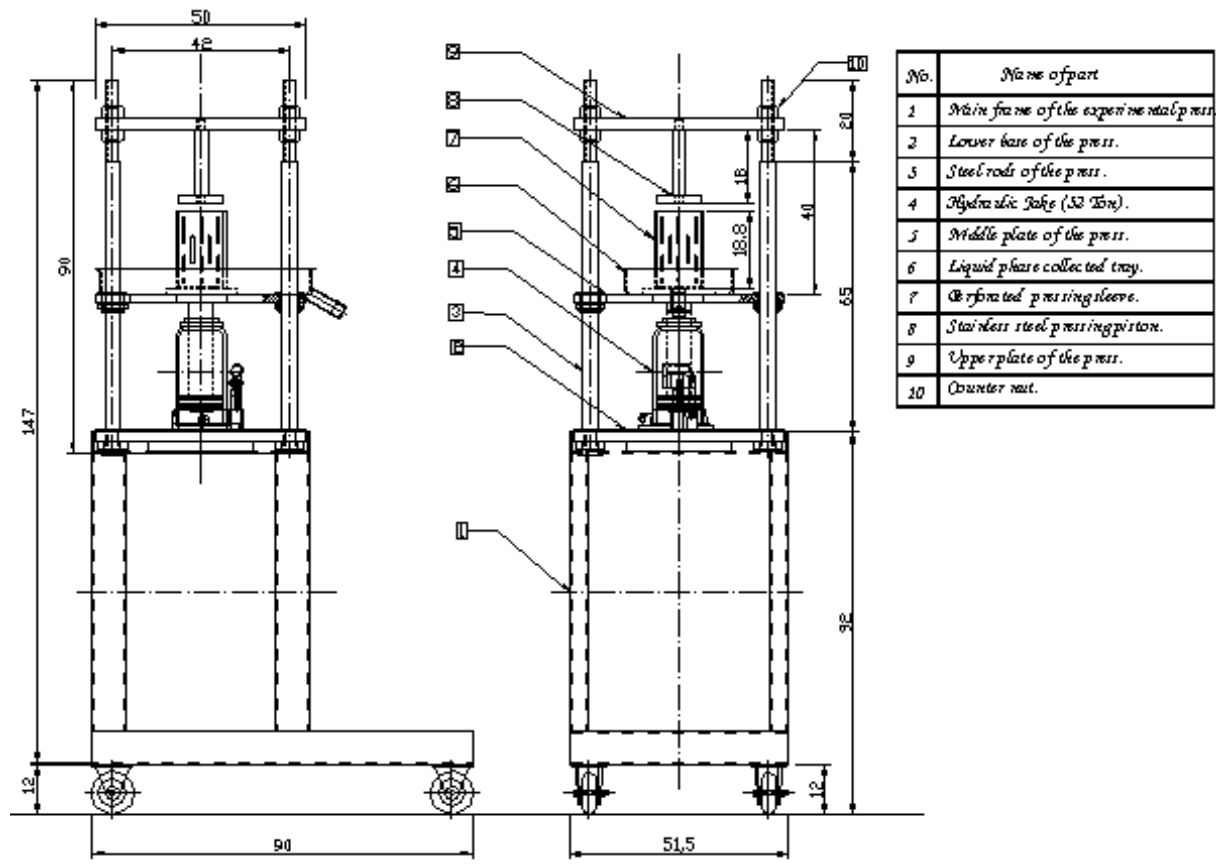

Fig.(3) Schematic diagram of the hydraulic press unit

The oil extraction was conducted using the hydraulic press unit at different applied pressures and holding times. For each experimental run, a samples of bran (raw or stabilized) were dispersed inside cotton mats 
and steamed for different steaming times. The mats of the steamed bran were vertically placed inside the perforated stainless steel cylinder and the hydraulic press unit was manually operated to increase the pressure load gradually over the mat surface until reaching the required pressing pressure. At this point, a stop watch was used to determine the holding time for each treatment under the condition of keeping the pressure constant all over the pressing period using the manual handle and the pressure gage of the hydraulic press unit. As the liquid phase separated from the bran, the resulted bran cake was mixed and used to determine the remaining amount of oil. $5 \mathrm{~g}$ of the dried samples were rolled inside a filtration paper (12.5 Watman) and installed inside a socselette solvent oil extractor using petroleum-ether at $40-60{ }^{\circ} \mathrm{C}$ for 16 complete circles, then it was allowed to dry in an electric oven at $70{ }^{\circ} \mathrm{C}$ for two hours in order to completely evaporate the remaining solvent from the sample. The obtained samples were again weighed and the percentage of remaining oil was calculated using the following equation:

Remaining oil $\%=\left(\mathrm{w}_{\mathrm{r}} / \mathrm{w}_{\mathrm{t}}\right) \times 100$

Where:

$$
\begin{aligned}
& \mathrm{W}_{\mathrm{r}}=\text { Weight of remained oil, } \mathrm{g} . \\
& \mathrm{W}_{\mathrm{t}}=\text { Weight of the bran sample, } \mathrm{g} .
\end{aligned}
$$

The extraction efficiency was determined using the following equation:

Extraction efficiency $=\mathrm{O}_{\mathrm{t}}-\mathrm{O}_{\mathrm{r}} / \mathrm{O}_{\mathrm{t}}$

Where:

$$
\begin{aligned}
& \mathrm{O}_{\mathrm{r}}=\text { remained oil, } \% \\
& \mathrm{O}_{\mathrm{t}}=\text { total oil in sample, } \%
\end{aligned}
$$

\section{Experimental Measurements:}

\section{Moisture content of rice bran}

The standard air oven method using five grams sample placed in air oven at $135{ }^{\circ} \mathrm{C}$ for $3 \mathrm{~h}$. used for measuring bran moisture content as recommended by A.O.A.C. (1991).

\section{Temperature measurements}

The universal digital measuring system model (Kega dig. 14) was used to measure rice bran bulk temperature during the steaming process while, the remote type-infrared spot thermometer model (HT11) used to measure the rotary cylinder surface temperature of the heat stabilization unit. It 
was also used for measuring the rice bran bulk temperature at the discharge point of the heating unit.

\section{Free fatty acids percentage (FFA\%)}

The FFA $\%$ of oil samples were calculated as oleic acid using the corresponding acid value of each sample according to the A.O.A.C.(1991) as follows:

$$
\begin{gathered}
\text { FFA } \%=\frac{282 * 100 * \text { Acid Value }}{56.1 * 1000} \\
\text { FFA } \%=\frac{\text { A. V }}{1.99}
\end{gathered}
$$

Where the values 282, and 56.1 refers to the equivalent weight of oleic acid and the potassium hydroxide $(\mathrm{KOH})$ respectively.

\section{RESULTS AND DISCUSSION}

\section{Bulk temperature and moisture content of the stabilized bran:}

After heating process at $95{ }^{\circ} \mathrm{C}$ and exposure time of $10 \mathrm{~min}$ using the rotary conduction heating unit. The bran bulk temperature increased with the increasing of exposure time and approached a level of $90.2{ }^{\circ} \mathrm{C}$ at the end of heating period. While the final moisture content of the stabilized bran approached about $8.33 \%$ w.b. in comparison with $13.46 \%$ for the raw bran. The percentage of free fatty acids (FFA) immediately after heat treatment approached about $2.16 \%$ for the stabilized bran in comparison with $2.65 \%$ for the raw bran. It should be mentioned that the difference in percentage of free fatty acid for the stabilized and the raw bran become obvious after the extraction process and storing the extracted oil for 15 days.

\section{Bulk temperature and moisture content of the steamed bran:}

Figure (4) presents the change in bran bulk temperature as related to steaming period for both raw and stabilized bran. As shown in the figure, bran bulk temperature increased with the increase of steaming period. The recorded bran bulk temperatures at steaming periods of $(20,25,30$ and 35 min) were 85.27, 88.33, 90.93 and $92.9{ }^{\circ} \mathrm{C}$ for the raw bran in comparison with $84.63,86.93,89.83$ and $91.70{ }^{\circ} \mathrm{C}$ for the stabilized bran respectively. On the same time Figure. (5) shows that, at steaming periods 
of $(20,25,30$, and $35 \mathrm{~min})$ the moisture content of raw bran increased from an initial level of $13.46 \%$ w.b. to final levels of $15.05,15.13,15.33$ and $15.8 \%$ respectively. While the the stabilized rice bran moisture content increased from an initial level of $8.33 \%$ w.b. to final levels of $12.13,13.46,13.7$ and $14.26 \%$ respectively.

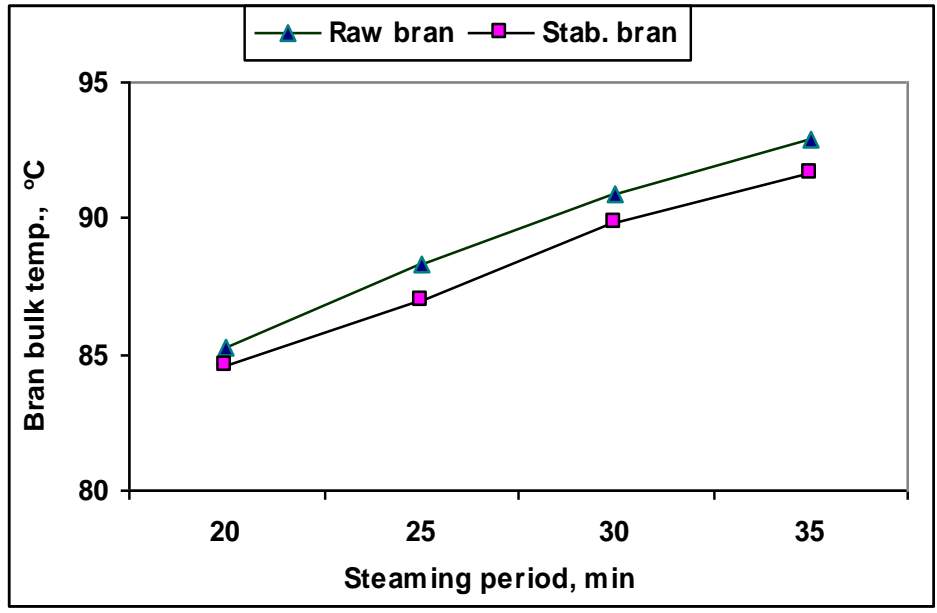

Fig. (4) Change in bran bulk temperature as related to steaming period

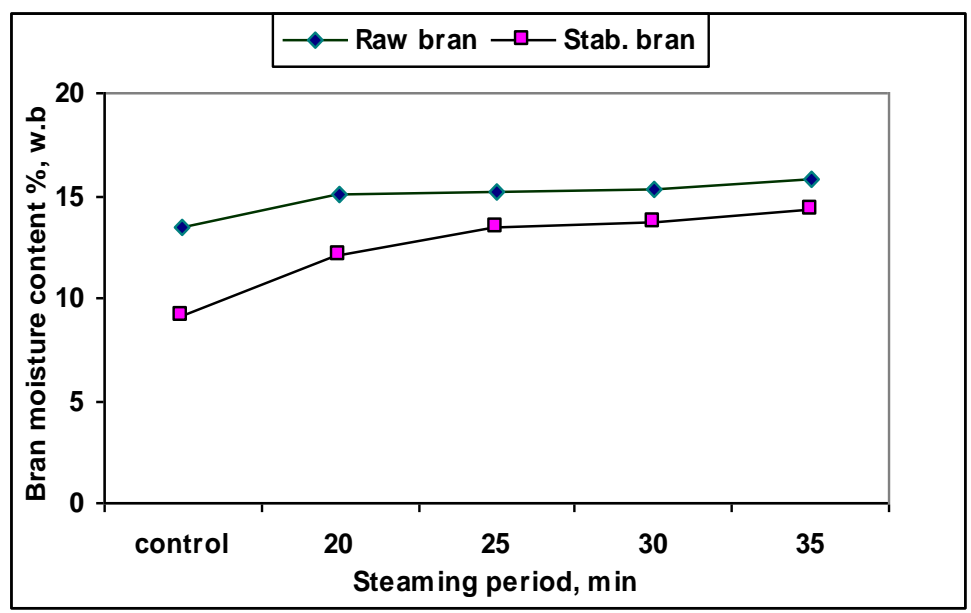

Fig. (5) Change in bran moisture content as related to steaming period Effect of applied pressure and holding time on bran moisture content Figures (6) and (7) illustrate the effect of applied pressure and holding time on moisture content of the raw and stabilized bran. As shown in figures, at all levels of applied pressure the moisture content of bran 
samples (raw and stabilized) gradually increased with the increase of holding time up to 20 mines and starts to decrease again at the holding time of $25 \mathrm{~min}$. This means that with the increase of both applied pressure and holding time, the moisture content at the bran cells starts to release out and increases the overall moisture content of the samples. However, with further increase of the applied pressure, the resulted temperature starts to heat the samples and part of the moisture starts to evaporate causing an overall reduction in the samples moisture content.

Effect of steaming period, applied pressure and holding time on extraction efficiency of oil :

Figures (8) and (9) illustrate the effect of steaming period, applied pressure and holding time on the extraction efficiency of oil from raw and stabilized bran respectively. As shown in the figures, under all levels of applied pressure and holding time, the un-steamed bran samples recorded lower extraction efficiency in comparison with the steamed samples. This condition may be due to the fact that steaming process free the lipids from other components and facilitating the oil release from the bran cells as mentioned by ( Bor, 1991 and David, 1990). The figures also showed that the extraction efficiency increased with the increase of steaming period, applied pressure and holding time. For the raw bran treated at the minimum applied pressure of 150 bar and holding times of 10, 15, 20, and $25 \mathrm{~min}$, the extraction efficiency increased from (17.0 to $31.1 \%),(23.10$ to $34.1 \%),(24.5$ to $37.1 \%)$, and (26.7 to $37.8 \%$ ) as the steaming time increased from 20 to 35 min respectively. While at the maximum applied pressure of 275 bar it was increased from (34.33 to 41.15\%), (35.11to $41.87 \%$ ), (36.45 to $45.29 \%$ ), and (37.94 to $46.98 \%)$ respectively. Meanwhile, for the stabilized bran treated at the applied pressure of 150 bar and holding times of 10,15, 20, and $25 \mathrm{~min}$, the extraction efficiency increased from (15.20 to $23.94 \%)$, (17.42 to $23.94 \%)$, (21.72 to $32.26 \%$ ), and $(22.83$ to $35.55 \%$ ) as the steaming time increased from 20 to $35 \mathrm{~min}$ respectively. However, at the applied pressure of 275 bar it was increased from $(24.11$ to $31.38 \%)$, (26.28 to $37.21 \%)$, (30.03 to $37.29 \%$ ), and (31.33 to $38.19 \%$ ) respectively. Similar trends were observed at the applied pressures of 175, 200, 225, 250 bar respectively. The above mentioned results revealed that, the extraction efficiency of the stabilized bran was slightly lower than that of the raw bran. This condition may be due to the lower levels of moisture content in the stabilized bran in 
comparison with the raw bran which causes lower rates of freeing the lipids from other components as mentioned by (Bor,1991).
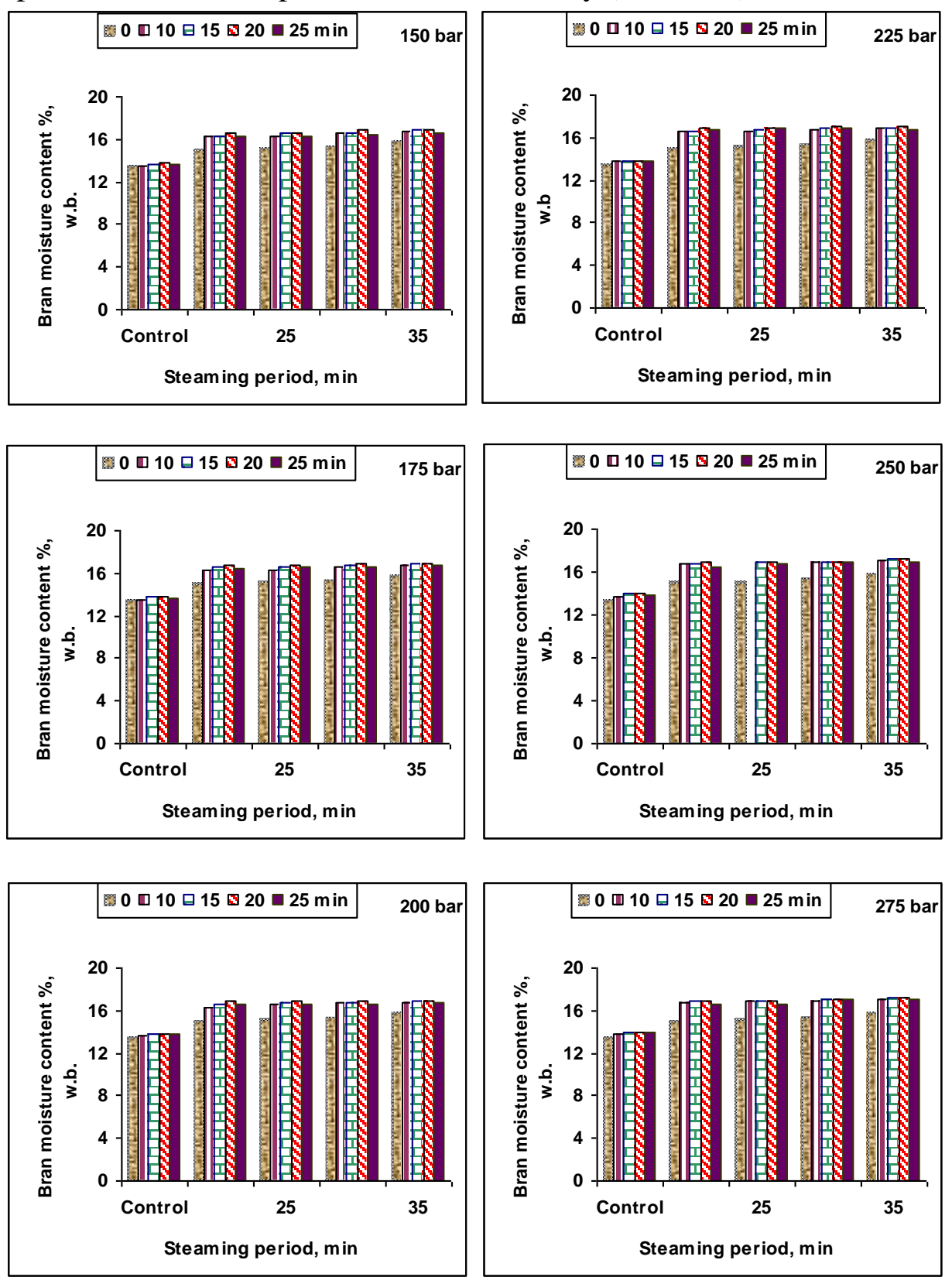

Fig.(6) Effect of steaming period and holding time on moisture content of the raw bran at different applied pressures 

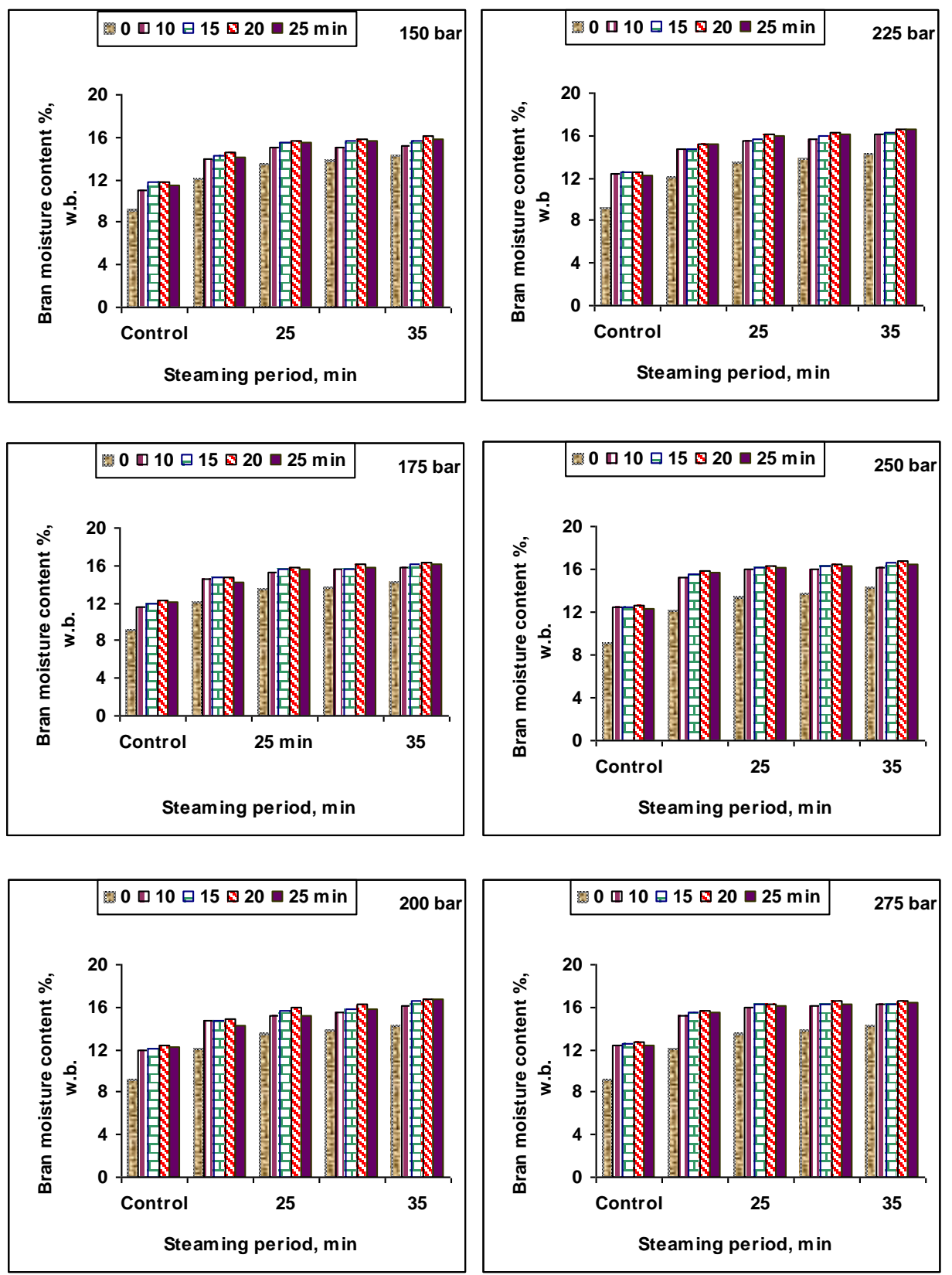

Fig.(7) Effect of steaming period and holding time on moisture content of the stabilized bran at different applied pressures.

To relate the changes in extraction efficiency $\left(\mathrm{E}_{\mathrm{f}}\right)$ with the steaming period $\left(\mathrm{S}_{\mathrm{t}}\right)$, applied pressure $\left(\mathrm{P}_{\mathrm{a}}\right)$, and holding time $\left(\mathrm{H}_{\mathrm{t}}\right)$. A regression analysis was employed, a generalized relationships between the extraction efficiency and other parameters were obtained for both raw and stabilized bran as presented in table (1).

Table (1): Equations relating the steaming period, applied pressure, and holding time with the extraction efficiency. 


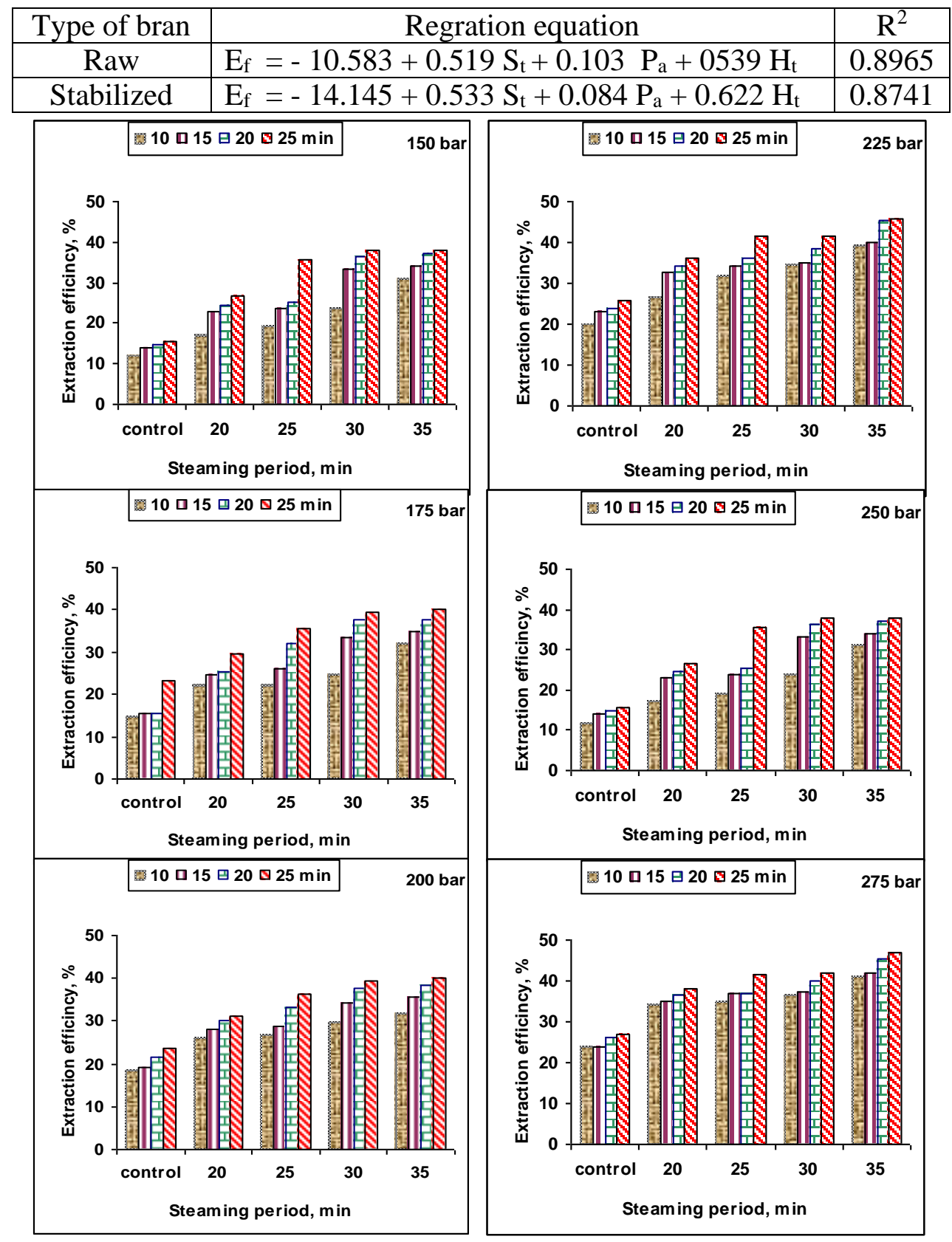

Fig. (8) Effect of steaming period and holding time on extraction efficiency, $\%$ of the raw bran at different applied pressures. 


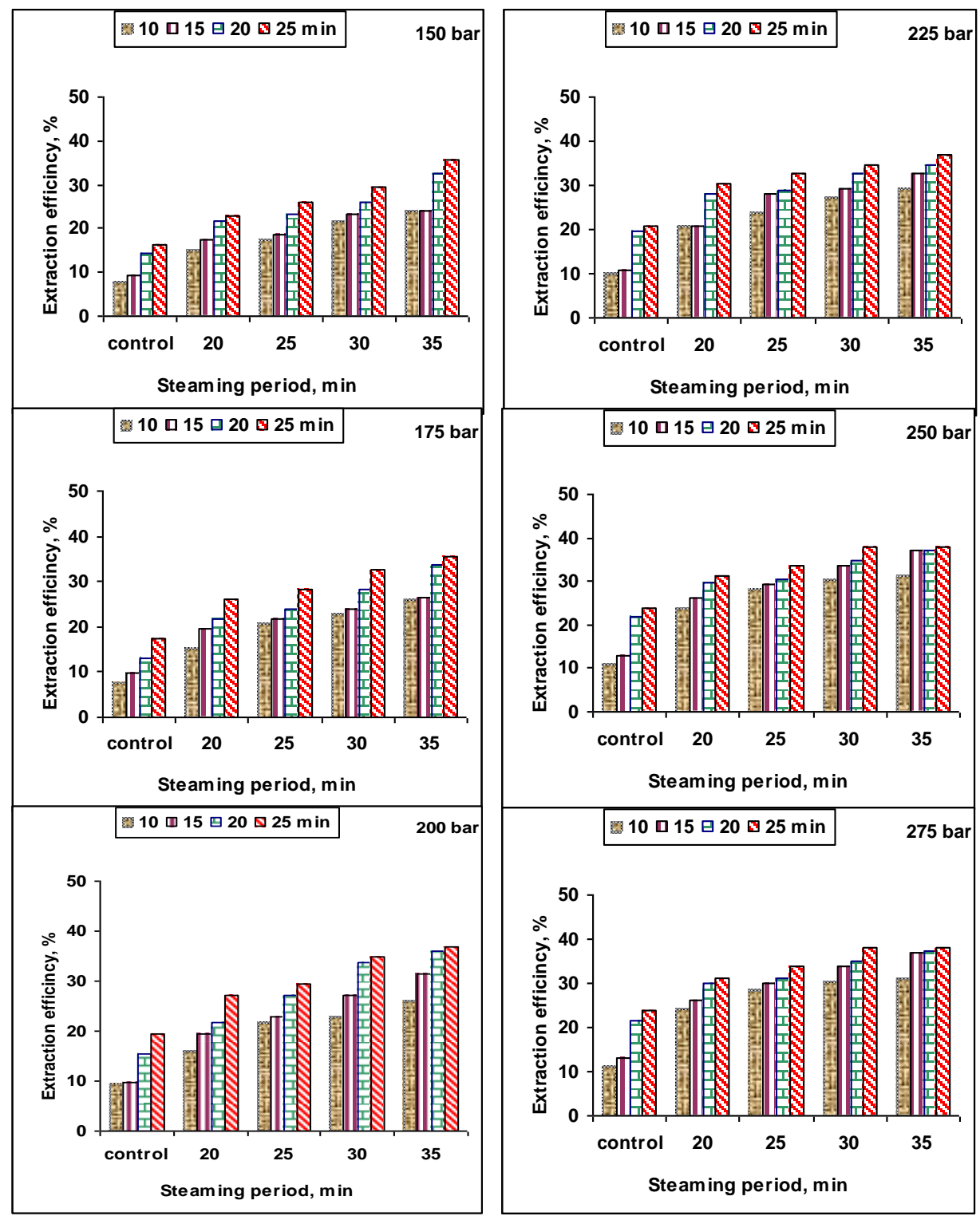

Fig.(9) Effect of steaming period and holding time on extraction efficiency, $\%$ of the stabilized bran at different applied pressures.

Effect of stabilization process on percentage of free fatty acids (FFA) in the extracted oil:

Figures (10) and (11) show the effect of stabilization process on the percentage of (FFA) under different steaming period, applied pressure and holding times. As shown in the figures, the raw bran treated at the 
minimum steaming time of $20 \mathrm{~min}$ and holding time of 10 min showed an increase in FFA \% from an initial level of $2.65 \%$ to final levels of 4.46, 4.56, 4.56, 4.58, 4.61 and $4.67 \%$ at applied pressures of 150, 175, 200, 225, 250 and 275 bar, respectively. While, at the maximum steaming time of $35 \mathrm{~min}$ and holding times of $25 \mathrm{~min}$, the percentage of FFA increased from an initial level of $2.65 \%$ to final levels of 5.09, 5.17, 5.19, 5.26, 5.39 , and $5.46 \%$ respectively.

Meanwhile, the stabilized bran treated at the minimum steaming time of $20 \mathrm{~min}$ and holding time of $10 \mathrm{~min}$ showed an increase of the FFA\% from an initial level of $2.16 \%$ to final levels of 2.83, 2.83, 2.98, 3.09, 3.12 and $3.17 \%$ respectively. However, at maximum steaming time of 35 min and holding time of $25 \mathrm{~min}$ the (FFA\%) increased from an initial level of $2.16 \%$ to final levels of $3.23,3.46,3.46,3.65,3.75$ and $3.75 \%$ respectively. The above mentioned results revealed that both the applied pressure and the holding time have a slight effect on the percentage of FFA. However, the heat stabilization process inactivate the lipolytic enzymes (lipases) present in native bran and minimize the increase of (FFA\%) in the extracted oil as mentioned by ( Bor, 1991 and Wakako et. al., 1994). In general, heat stabilization of the bran samples prior to steaming process slightly decreased the extraction efficiency of the bran oil. However, it has greatly decreased the percentage of free fatty acids in the extracted oil and may keep the oil more stable during the storage process. To relate the changes in FFA \% with the steaming period $\left(\mathrm{S}_{\mathrm{t}}\right)$, applied pressure $\left(\mathrm{P}_{\mathrm{a}}\right)$, and holding time $\left(\mathrm{H}_{\mathrm{t}}\right)$. A regression analysis was employed, a generalized relationships between the FFA \% and other parameters were obtained for both types of bran (raw and stabilized) as presented in table (2).

Table (2): Equations relating the steaming period, applied pressure, and holding time with the percentage of (FFA).

\begin{tabular}{|c|c|c|}
\hline Type of bran & Regression equation & $\mathrm{R}^{2}$ \\
\hline Raw & FFA $=2.029+0.0404 \mathrm{~S}_{\mathrm{t}}+0.0029 \mathrm{P}_{\mathrm{a}}+0.01 \mathrm{H}_{\mathrm{t}}$ & 0.934 \\
\hline Stabilized & FFA $=1.963+0.0245 \mathrm{~S}_{\mathrm{t}}+0.002 \mathrm{P}_{\mathrm{a}}+0.009 \mathrm{H}_{\mathrm{t}}$ & 0.912 \\
\hline
\end{tabular}



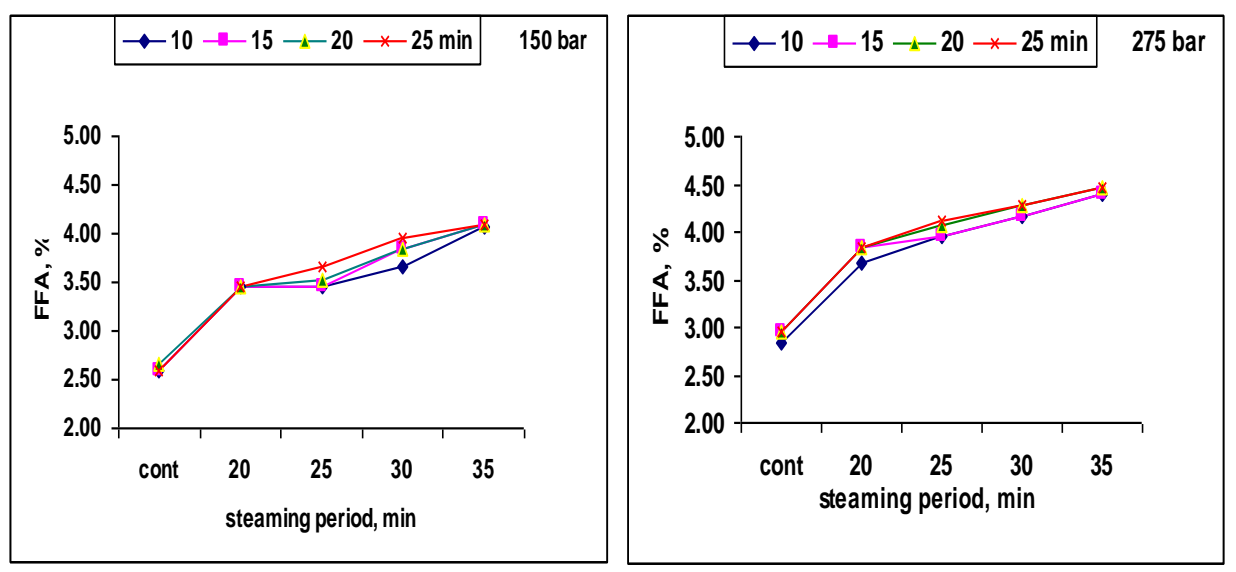

Fig. (10) Effect of steaming period, applied pressure, and holding time on

FFA $\%$ of the raw bran.
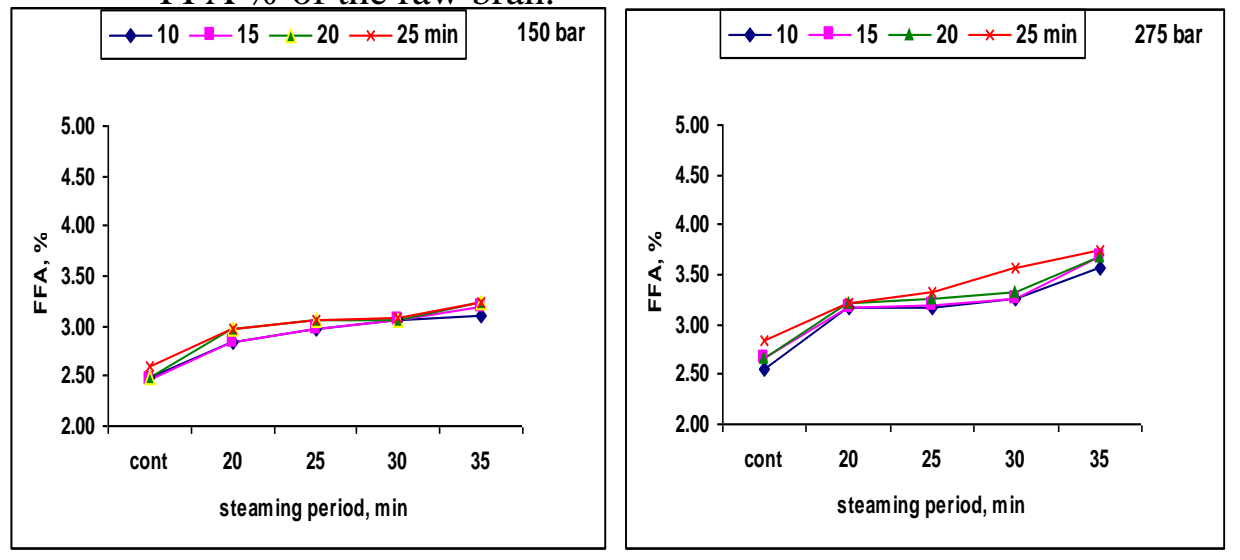

Fig. (11) Effect of steaming period, applied pressure, and holding time on FFA $\%$ of the stabilized bran.

\section{CONCLUSIONS}

1- The final bulk temperature of the stabilized bran approached about $90.2{ }^{\circ} \mathrm{C}$. While the moisture content was about $8.33 \%$ w.b. in comparison with $13.46 \%$ for the raw bran.

2- The moisture content of raw bran increased with steaming period from $13.46 \%$ w.b. to final levels of $15.05,15.13,15.33$ and $15.8 \%$ at steaming times of $20,25,30$ and 35 min respectively. 'While the stabilized rice bran moisture content increased from $8.33 \%$ w.b. to final levels of $12.13,13.46,13.7$ and $14.26 \%$ respectively.

3 - For both raw and stabilized bran the highest extraction efficiency was obtained at applied pressure of 275 bar and holding time of $25 \mathrm{~min}$. 
While the extraction efficiency of the raw bran ranged from (17.00 to $46.98 \%$ ) in comparison with (15.20 to $38.11 \%$ ) for the stabilized bran.

4- Heat stabilization of the bran samples prior to steaming process decreased the percentage of free fatty acids in the extracted oil and may keep the extracted oil more stable during the storage process.

\section{REFERENCES}

A.O.A.C (1991): Association of Official Agriculture Chemists. Official Methods of Analysis of 15 th ed., D.C. USA.

Bor, S. L. (1991). Rice oil in rice utilization. Pp 295:311. An Avl Book published at Van Nostrand Rieinhold New York.

Daniel, M. J., G. Samuel, S. Gladness, V. Lalit and H. John. (1993). Optimizing rice bran stabilization by extrusion cooking. Louisiana Agriculture, 36: 13-15.

Gupta, H. P. (1989). The solvent extractors Associton of India. Rice bran offers India an oil source. J. AOCS, vol 66.

Hendawy, Y. T. (2003). Effect of heat stabilization process on storage period and quality deterioration of rice bran. Unpulished M.Sc. Thesis, Dep.Of Agr. Engneering. Fac. of Agr. Mansura Univ.Egypt.

Khan, L.M. and M. A. Hanna (1983). Expression of oil from oilseeds a review. J. Agric Eng. Res. Vol. 28;495-503

Koga, Y. (1980). Small -scale rice bran oil extraction system using an expeller. AMA. Vol . X1, No.4: 65-68.

Matouk, A. M., M.M.El-kholy,T. R. Owies and A. Tharwat (2003). Factors affecting crushing and extracting of olive oil. Egypt. J. ), Agric. Res.86 (1) 2008.

Most M. M; R. Jully; S. Morales; and M. lefevre (2005). Rice bran oil not fiber lower cholesterol in humans. American Journal of Clinical nutrition, vol. 81, No. 1, 64-68.

Singh, M. S.; A. Farsaie, L. E. Stewart and L. W. Douglass (1984). Development of mathematical models to predict sunflower oil expression on Transaction of the ASAE,27 (4): 1190- 1194.

Sivala, K.; N. G. Bhole; and R. K. Mukherjee (1991). Effect of moisture on rice bran oil expression .J. Agric. Eng.. Res. 50: 81-91.

Misr J. Ag. Eng., January 2009 
Wakako, T.; H. Kasumimoyo; and T. Suzuki (1991). Esterase activity and free fatty acid accumulation in the bran of selected rice cultivars. Cereal Chemistry 71 (2): 162-165.

Yoon, S. H. and S. K. Kim. (1994). Oxidative stability of high fatty acid rice bran oil at different stages of refining. JAOCS, vol. 71 No.2.

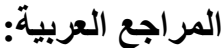

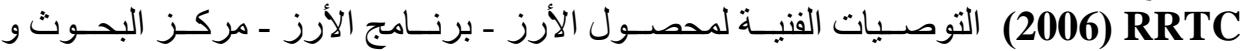
التدريب فى الأرز مركز البحوث الزراعية.

الملخص العزبي

العوامل المؤثرة على استخلاص زيت رجيع الأرز باستخدام

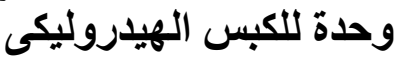

أحمد محمود معتوق('), محمد مصطفى الذولى("), مجدى السعدنى("), ياسر طلبة هنداوى(")

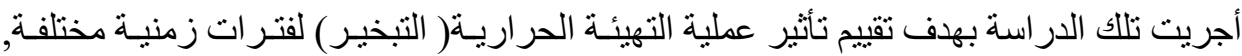

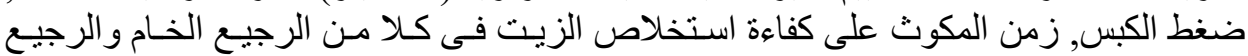

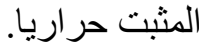
وقد أمكن تلخيص النتائج المتحصل عليها فيما يلى : النيا

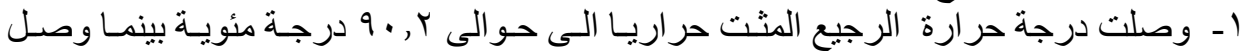

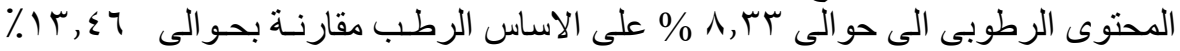

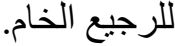

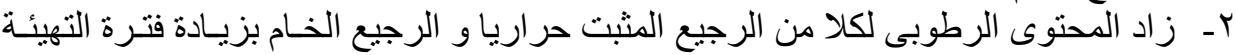

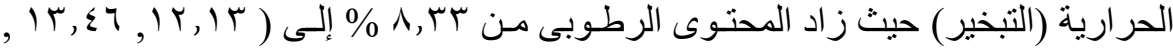

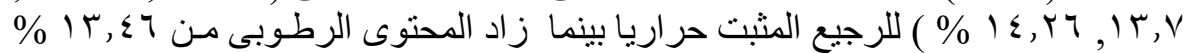

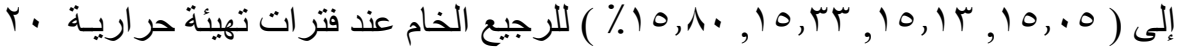

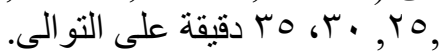

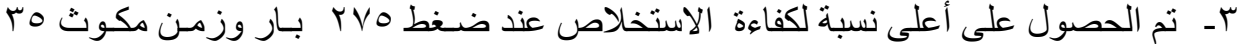

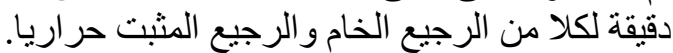

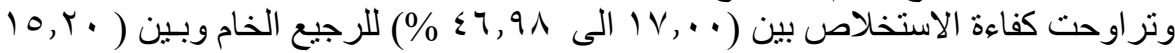

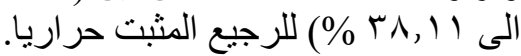

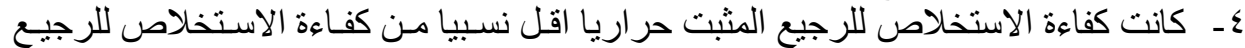

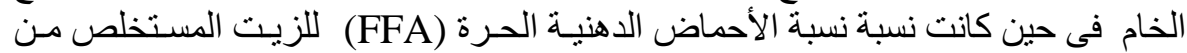

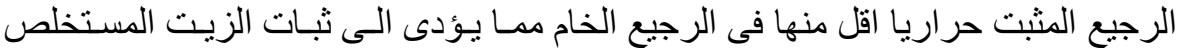

أنثاء عملية النخزين

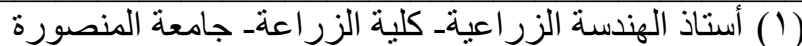

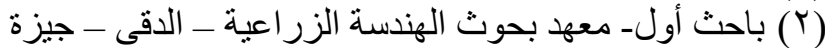

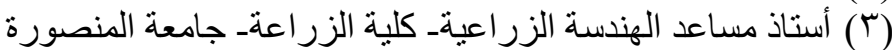

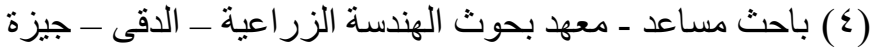

